\title{
RECETA MÁGICA PARA UN INFANTE ENFERMO (KTU 1.124)
}

\author{
G. DEL OLMO LETE
}

Universidad de Barcelona

El texto ugarítico KTU 1.124 ' representa un caso peculiar de consulta cúltica acerca de un "infante» (regio), al parecer gravemente enfermo. En el mismo, el rey, en su calidad de "Señor de los dioses/espíritus grandes/superiores" ( $a d n \mathrm{ilm} \mathrm{rbm})^{2}{ }^{2}$, es decir, de los miembros muertos y divinizados de la dinastía ${ }^{3}$, se dirige en consulta cultual al legendario y divino fundador de la misma Ditānu, a pedir el "decreto" (mtpt) o respuesta oracular, la "palabra de Dios" que es ley y oráculo a la vez ${ }^{4}$. Así como es improbable suponer que sea

${ }^{\prime}$ El último tratamiento del texto por M. DieTrich - O. LoRETZ. Mantik in Ugarit. Keilalphabetische Texte der Opferschau-Omensammlungen-Nekromantie, Münster 1990, págs. 205-240, ofrece una nueva lectura y discusión del mismo, junto con una referencia completa de la bibliografia pertinente (págs. 205-207, 239-240). Añadir: A. CAQUOT, "Hébreu et Araméen II (séminaire)", Annuaire du Collège de France LXXV (1975) 429: B. PolENTZ. "Medizinhistorische Bemerkungen zu KTU 1.124 und RIH 78/20". Materiali lessicali ed epigrafici I (1982) 47-50; B. LEVINE - J. M. DE TARRAGON. "Dead Kings and Rephaim: The Patrons of the Ugaritic Dynasty", Journal of the American Oriental Society CIV (1984) 655, n. 29; D. PARDEE, "Marim in Numbers V"; Vetus Testamentum XXXV (1985) 112 (y su revisión en Les textes paramythologiques de la $24^{e}$ campagne (1961), Paris 1988, págs. 179-192). El estudio de Dietrich - Loretz, así como el de A. Caquot (A. CaQuot - J. M. DE TARRagon - J. L. Cunchillos, Textes Ougaritiques. Tome II: Textes religieux et rituels. Correspondence, Paris 1989, págs. 119-123 [TOu I ]), nos servirán de punto de partida y ahorrarán la referencia detallada a trabajos anteriores.

${ }^{2}$ Para las diferentes interpretaciones de esta figura (Ilu, Baclu, Yaqaru, sacerdote conjurador; vid. hebreo $\left.b^{\prime} l t{ }^{\prime} w b\right)$ cf. M. DieTrICH - O. LORETZ, Mantik, págs. 214216; A. CAQUOT, TOu II, pág. 121, n. 368. Adviértase que adn es título regio-divino, posiblemente empleado aquí en su sentido propio; cf. G. Del Olmo LeTE, "Los nombres 'divinos' de los reyes de Ugarit", Aula Orientalis V (1987) pág. 58; "Textos ugaríticos y su crítica literaria", Aula Orientalis VIII (1990) pág. 186.

${ }^{3}$ Cf. M. DieTrich - O. LoreTz. Mantik, pág. 215. En KTU 4.149:1-2 se menciona su templo (bt ilm rbm) al que se destina una jarra $(k d)$ de vino, mientras dos $(k d m)$ van al \$b de Ishara (1. 13) y "cinco al dbh de la reina en el sembrado". El contexto de culto regio-funerario es patente: vid. M. DieTrich - LoRETZ, Mantik, pág. 218.

4 Cf. M. Dietrich - O. Loretz, Mantik, págs. 216, 226-239; A. CAQUOT, TOu II, pág. 121, n. 371 (cf. Hebreo sll msp.t). 
Ilu, el dios supremo, el que se presenta ante Ditānu, no lo es menos que, en un protocolo de consulta oracular reclamada por el rey, no se le mencione a él como demandante principal y sí, en cambio, al adivino intermediario, siendo aquél el responsable supremo del culto adivinatorio en Ugarit, el que «da respuesta» ( $\underline{\underline{t} \underline{t}} \mathrm{rgm})$ y "visita" (yph) a los dioses (cf. KTU 1.90:1 RIH. 77/2B:11 77/10B:1, 8). En nuestra interpretación, el rey aparece como sujeto explícito de la consulta, mientras queda implícito el funcionario cúltico al que va dirigida la respuesta que ha de transmitir a aquél. De otra manera se hace muy difícil de entender la súbita referencia a «tu mensajero» en 1. 11, relacionada con el rey '. A Ditānu se dirige, por su parte, también la reina en un rito sacrificial, aunque no podemos precisar el motivo concreto del mismo (cf. RIH 78/11:1-2).

La respuesta que recibe (del funcionario cultual) es doble: se le dice que cumpla primero una acción ritual de magia simpatética en los templos de Hôrānu y $B a^{c} l u$, y que venga luego su mensajero a recoger tal decreto, la respuesta de Ditānu, resultante, sin duda, de aquella acción ritual, y que especifica a la vez su continuación, igualmente ritual, en palacio (vid. 1. 14) ${ }^{6}$. Sea cual sea su interpretación, tal respuesta es el oráculo que fija la suerte del infante regio (yld) ${ }^{7}$ y muestra la preocupación que el soberano de Ugarit tenía por él. Se entiende corrientemente como una consulta cultual en relación con la salud/enfermedad del príncipe regio, quizá el heredero (cf. $2 \operatorname{Re} 1,2$ ss.; vid. Jue 13,12).

5 M. Dietrich - O. Loretz, Mantik, pág. 218, ven bien la dificultad: “Da bisher in KTU 1.124 der Protokollant ohne Anrede ausgekommen ist und für eine solche hier kein unmitellbarer Anlass $\mathrm{zu}$ erkennen ist, durfte eine Dittographie des $k$ nicht auszuschliessen sein". No se precisa suponer esto si se distribuyen los sujetos de la manera propuesta. Por su parte, también A. CAQuOT, TOu II, pág. 121, n. 373, advierte el problema: "La répétition du verbe 'répondre', à la 2 e personne maintenant, ne s'explique que si trois personnages sont en jeu: le 'maître des dieux' qui fait visite à Ditanu, Ditanu lui-mème et quelqu'un qui a dâ venir le consulter et auquel il transmet la 'décision' du 'maître des dieux'».

${ }^{6}$ No es preciso, pues, suponer que las líneas (13) 14-16 sean un 'apéndice' que debería ir unido a la línea 10; cf. M. Dietrich - A. Loretz, Mantik, pág. 220. En cuanto a la figura del mensajero, resulta curioso constatar su presencia también junto al dios mlk'strt en las inscripciones de Umm el-'Amed; cf. G. DEL OLMO LETE, "Pervivencias cananeas (ugaríticas) en el culto fenicio - III", Sefarad LI (1991) 99-114, 105-106. En las consultas bíblicas, la recurrencia del mensajero (malaak) del rey y de Yahweh es constante (cf. Jue 13,3 ss.; 2 Re 1,2 ss.).

${ }^{7}$ Cf. M. Dietrich - O. Loretz, Mantik, pág. 217. De acuerdo con KTU 1.23:53 y 1.103:2, yld es el neonato. Entre las cartas de Mari tenemos un buen ejemplo de decreto oracular que sentencia la suerte, en este caso la muerte, de una infanta regia recién nacida; cf. W. Malamat, «Parallels between the New Prophecies from Mari and Biblical Prophecy: I) Predicting the Death of a Royal Infant», N.A.B.U. 88 (1989) 61-63. 
Consideramos aquí este texto, en razón de su contexto palatino, como protocolo de una consulta regia, pero podría entenderse también como manual de consulta adivinatoria para uso del sacerdote adivino en cuya casa se encontró, junto con otros muchos elementos de su función ${ }^{8}$. Constituiría así un modelo de respuesta estándar para casos de enfermedad infantil. Lo peculiar de éste es que la consulta la hace el rey y va dirigida al dios Ditānu, el antepasado legendario de la dinastía. Se ha pretendido que éste se hallaría representado por su estatua ${ }^{9}$, en cuyo caso sería más verosímil suponer que la consulta se lleva a cabo en el santuario palatino, el de los manes de la dinastía ${ }^{10}$, de la que la tablilla sería el formulario conservado por el nigromante en su archivo. De tal ritual sería una explicación perfecta Os 4,12, que nos habla de ídolos de madera a los que se presta un oráculo (vid., también 2 Re 1,2 ss., consulta en santuario), así como la aparición, en las excavaciones, de estatuas con orificios que hacen suponer su utilización para emitir oráculos.

Pero podría tratarse igualmente de una evocación, al estilo de 1 Sam 28,3 ss. (la nigromante de Endor, $b^{c} l t{ }^{\prime} w b$ ), llevada a cabo por el sacerdote nigromante en su propia casa o santuario privado, donde apareció la tablilla, protocolo así de la consulta cultual concreta ". El texto es el siguiente, de acuerdo básicamente con la lectura propuesta por Pardee, Dietrich y Loretz:

${ }^{1} k$ ymgy $a d n$

${ }^{2}$ ilm.rbm. ' $m$ dtn

${ }^{3}$ wysal.mtpt.yld

"wy'ny.nn dtn

${ }^{\text {st'ny }}$

nad.mr. qh

${ }^{6} w s t . b[b] t . h r n$

trh ${ }^{7} h d t m[r] q h[$.

wst ${ }^{8} b b t . b \% l$.

bnt.gh

${ }^{9} w s t . b b t$
Cuando se acerque/ó el Señor

de los grandes dioses ante Ditänu

a preguntarle por el decreto del infante

le responderá/ió Ditānu:

"Responde[d]:

"una bolsita de mirra coge

y pon[la] en el templo de Hórānu;

un tarrito de mirra nueva coge

y pon[lo] en el templo de $B a^{c} l u$;

[un hacecillo de] tamarisco ${ }^{12}$ coge

$y$ pon[lo] en el palacio,

${ }^{8} \mathrm{El}$ protocolo implicaría la versión en pasado (conversivo); el formulario-manual, en futuro, el modo más normal de la forma verbal en prosa.

${ }^{9}$ Cf. M. Dietrich - A. LORETZ, Mantik, pág. 225.

${ }^{10} \mathrm{Cf}$. a este propósito J. TROPPER, Nekromantie. Totenbefragung im Alten Orient und im Alten Testament, Neukirchen-Vluyn 1989, pág. 154.

$"$ Cf. M. Dietrich - O. Loretz, Mantik, pág. 226.

12 Ibid., pág. 218; A. CAQUOT, TOu II, pág. 122, n. 377 (acadio blnu); pero en contextos rituales y mágicos el vocablo normal por tamarisco es 'rer (vid. KTU 1.109:29; 
wprt ${ }^{10}$ hy.hlh.

wymǵ ${ }^{11}$ mlakk.'m din

${ }^{12}$ lqh mtpt

${ }^{13}$ wy'ny.nn ${ }^{14} \mathrm{dtn}$

bin.mhy

${ }^{15}$ ldg wlkll]

${ }^{16}$ watr.in.mr y éste hará desaparecer ${ }^{13}$ su mal.

Y que venga [luego] tu mensajero ante Ditānu

a recoger el decreto"».

Y le responderá/ió [entonces] Ditānu:

"El interior de la casa ${ }^{14}$ limpia:

nada de pescado y esto en absoluto ${ }^{15}$,

y en lo sucesivo no habrá amargor" ${ }^{16}$.

1.110:64-65). El valor 'estatuilla' de bnt no puede excluirse; cf. M. DieTrich - O. LORETZ, "Gebrauch von Götterstatuen in der Mantik von Ugarit (KTU 1.124)", UgaritForschungen 12 (1980) 396. A este propósito vid. la costumbre de enterrar figurillas (acadio urdimmu), hechas precisamente de madera de tamarisco, en el palacio: P.-A. BEAULIEU, "Lion-Man: ridimmu or urdimmu?", N.A.B.U, 121 (1990) 99-101; también B. Polentz, "Medizinhistorische", págs. 47-48, para otro tipo de paralelos. En la Sidón del siglo I era frecuente la ofrenda de estatuillas de infante como exvoto al dios curandero Eshmun; cf. B. SERVAIS - SOYEZ, "La 'Triade' phénicienne aux époques hellénistique et romaine», Studia Phoenicia IV, Namur 1986, pág. 354. Se trata en general, de un procedimiento de magia apotropaica, de manera que cuando la estatuilla incorpora un mal espíritu se la rompe; si representa uno bueno, se la conserva. El dios Ilu también recurre a un procedimiento similar (KTU $1.16 \mathrm{~V} 23 \mathrm{ss.)}$ para sanar al rey Kirta.

13 Frente al nuevo hápax pre prefiero leer (w)prt ("prr, cf. KTU 1.15 III 30) con valor consecutivo, reconociendo, no obstante, que la forma del signo favorece una lectura pr.

14 Cf. acadio bitänu, W. Von Soden, Akkadisches Handwörterbuch, Wiesbaden 1965, págs. 131-132; hebreo bytn, L. KOEHLER - W. BAUMGARTNER, Lexicon in veteris Testamenti libros, Leiden 1958, pág. 124; mejor que suponer aquí un -n elativo; vid. M. DiETRICH-O. LORETZ, Mantik, p. 218. Sin más, bt puede significar 'palacio' o 'templo'.

${ }^{15} \mathrm{El}$ texto parece retener restos de dos cuñas verticales, lo que sugiere la presencia de un signo $s / b$. La lectura kls resulta un hápax de valor incontrolable, mientras la lectura $k l b$, 'perro', es hipotética y su semántica en este contexto resulta extraña; cf. A. CAQUOT, TOu II, pág. 123, n. 381. Suponiendo la presencia/pérdida de una tercera cuña vertical y dejando de lado la incontrolable lectura $w l k \llbracket[d]$, preferimos leer wlk $\lfloor\backslash$ y tomarlo como expresión adverbial con w- enfático; para $l k\lceil l]$ con valor de 'en (su) totalidad, en absoluto' cf. KTU 1.16 I 45 (whrs lkl); por otro lado, el uso de kll, 'todo/todos', es normal en la prosa epistolar en la expresión 'mny kll [mid] $\mathrm{Slm}$, "cabe mí todo está [completamente] en paz" (cf. KTU 2.11:11; 2.13:10; 2.16:14; vid. también KTU 1.115:10). Por otra parte, KTU 1.106:21-22 nos ofrece curiosamente una expresión paralela $(w k l)$, referida al pescado $(d g)$ con presencia de ambos lexemas: wkl sbslt dg, "y toda clase de guisos de pescadon; la expresión tiene su confirmación en arameo, hebreo, y acadio. Otra posibilidad sería tomar $k l\left({ }^{*} k w / y l\right)$ en el sentido que parece tener el lexema en el calendario de Gezer:5. 'medición [del grano]', y por metonimia 'grano' (wlkl, "y nada de granow); tal lexema aparece también en el contexto que señala KTU 1.14 III 58; klt lhm; vid. ar. 'medida de grano', J. G. Hava, Al-Faraid. ArabicEnglish Dictionary, Beirut 1964, pág. 672. Para un paralelo de esta prescripción de ayuno profiláctico cf. B. PoleNTZ, "Medizinhistorische», pág. 50. Sintácticamente la construcción resulta la contrapartida volitiva de la indicativa $b l \mid l b l$ rbb... de KTU 1.19 I 44. No obstante, tal valor prohibitivo de $l$ - con substantivo no está certificado en ningún otro lugar, por lo que no es de descartar la interpretación que ve aquí el sintagma proposicional mky l- 'limpiar de', propuesto por J. TROPPER, Nekromantie, pág. 152, aunque tampoco éste aparece en ningún otro texto.

${ }^{16}$ Es decir, enfermedad; cf. D. PARDEE, «Marim», pág. 112. Adviértase el juego de palabras: $\mathrm{mr} / \mathrm{mr}$ (líneas $5 / 16$ ) 
No sabemos el modo como Ditānu y los antepasados de la dinastía (en su función de gtrm) ${ }^{17}$ articulaban esa palabra, ni cómo la percibía el mediador regio. En KTU 1.41:53 se asegura simplemente que el rey "hablará como le plazca», pero es dudoso el sentido oracular en este caso $\mathrm{y}$, de todos los modos, no se trata de un ritual funerario.

El texto KTU 1.124 resulta así un ejemplo típico, aunque aislado, de consulta/evocación adivinatoria como recurso cultual apto para encuadrar y garantizar determinados usos y recetas mágico-profilácticas que resaltaban el valor curativo de determinados productos y plantas, así como el de determinados tabúes alimenticios: recetas y tabúes de los que da testimonio toda la tradición oriental, incluida la hebrea. Constituyen así un elemento más de la homogeneidad cultural de toda la zona.

Invita asimismo a una ilustradora comparación con 1 Sam 28, el episodio de la pitonisa de Endor. El recién instaurado rey de Israel prohibe en su reino la nigromancia y toda otra adivinación funeraria ligada al culto de los muertos, típicamente cananeo, pero recurre a ellas al fallarle los sistemas yahvísticos de respuesta cultual (sueños, suertes y oráculos). Se entiende que la prohibición viene determinada por las exigencias de su fe, pero cabría preguntarse si no se debe a la defensa de un monopolio regio, heredado del modelo monárquico cananeo, por el cual el soberano se dirige al fundador de la dinastía, en este caso Samuel, para preguntarle por los asuntos del reino. Precisamente por esto conoce la nigromante que es el rey Saúl el disfrazado cliente que ha ido a su consulta ${ }^{18}$. Pero donde la permanencia del uso y creencia cananeos es más patente es en la fraseología usada por la nigromante para verbalizar su experiencia: "veo a un dios ('elohim) que asciende de la tierra/infierno" (1 Sam 28,13). Ésta es precisamente una de las denominaciones (ilh/ilhm) que reciben los reyes muertos y divinidades de Ugarit (KTU 1.39:5) ${ }^{19}$. A esa aristocracia regia se unirán también Saúl y sus hijos una vez muertos al día siguiente (v. 19).

Hay todavía otros aspectos que relacionan este texto bíblico con los usos cananeos, que aquí no podemos detenernos a analizar. En su conjunto resulta un espléndido ejemplo de la continuidad cultual que mantuvo Israel con su entorno cananeo-fenicio, apenas velada por la revisión yahvista posterior de su tradición.

17 Cf. G. DEL OlMo LETE, «Ritual regio ugarítico de evocación/adivinación (KTU 1.112)", Aula Orientalis II (1984) 201-203; "Los nombres", págs. 62-63.

${ }_{18} \mathrm{El}$ tema del disfraz aparece de manera relevante en la leyenda de Aqhatu (KTU 1.19 IV 43-46).

19 Cf. G. DEL Olmo LeTE, «Los nombres", págs. 41-43, 64-65. 


\section{RESUMEN}

El artículo analiza el texto ugarítico KTU 1.124 a partir de los últimos estudios sobre el mismo, ofreciendo nuevas opciones interpretativas. En este sentido se confiere a la expresión adn ilm rbm el valor del título regio referido al monarca que lleva a cabo la consulta cultual. Asimismo se sugiere una nueva versión del sintagma wlkl(1). Finalmente, se establece un cierto paralelismo entre el texto ugarítico en cuestión y 1 Sam 28.

\section{SUMMARY}

This article analyses the Ugaritic text KTU 1.124, departing from the later studies on it, and drawing forward some new insights. For instance, the expression adn ilm rbm is considered to be a royal title in connection with the sovereign that makes the cultic consultation. A new version is also suggested for the word wlkl(l). Finally, a certain parallelism between KTU 1.124 and the biblical text of 1 Sam 28 is pointed out. 